\title{
Monitoring and analysis of lowland river discharge
}

\author{
A.J.F. (Ton) Hoitink ${ }^{l, *}$ \\ ${ }^{1}$ Wageningen University and Research, Department of Environmental Sciences, Droevendaalsesteeg 3, \\ 6708 PB Wageningen, The Netherlands
}

\begin{abstract}
In single-thread channels with a sloping bed and quasi-steady con- ditions, river discharge can often directly be inferred from the water level using a rating curve. Challenges occur when the bed slope becomes negligibly small, or when the discharge becomes highly dynamic such as in the case of tides. This paper discusses recent work on monitoring and analysis of river discharge dynamics under such complicating circumstances. In lowland rivers, backwater has an effect on water levels that extends over a large region for smaller bed slopes. Results from a rainfall-runoff model and discharge measurements in the Mahakam catchment show that when a rating curve is developed in a backwater effected river, it essentially filters the backwater effects out of the discharge series. In coastal lowland plains, marine impacts cannot be ignored. Tidal waves may propagate hundreds of kilometers inland and interact with the river discharge. Acoustic Doppler current profilers are increasingly being employed for discharge monitoring in lowland rivers. A recently developed error model shows that the acoustic range needs to extend beyond the distance from the river bank where the depth mean flow velocity exceeds the cross-section averaged velocity.
\end{abstract}

\section{Introduction}

In alluvial rivers, gradients in flow velocity imply gradients in sediment transport, which results in mophological change. When the boundary conditions of the river are steady, or varying only slowly, the river may evolve towards a morphological equilibrium in which the flow and sediment transport are quasi-uniform and the bed profile is stable. In such conditions, the water surface slope equals the bed slope, and the potential energy or head loss exactly balances the energy loss by friction. Then, there exists a unique relation between stage and discharge, which is the basis for standard rating curves that adequately represent so-called kinematic discharge waves. In coastal lowlands, kinematic wave theory generally does not apply, and the discharge cannot easily be retrieved from a single water level gauge station. This contribution offers a brief overview of the causes of ambiguity in stagedischarge relations, by discussing the reasons for nonuniform flow and backwater in Section

\footnotetext{
*Corresponding author: Ton.Hoitink@wur.nl
} 
2 and the effect of tides in Section 3. Continuous measurement of flow velocity is an emerging means of collecting the additional information needed to estimate discharge in complex settings. Based on a recent contribution by Kästner et al. [2], Section 4 discusses the prerequisites for accurate monitoring of river discharge based fixed-location velocity measurements.

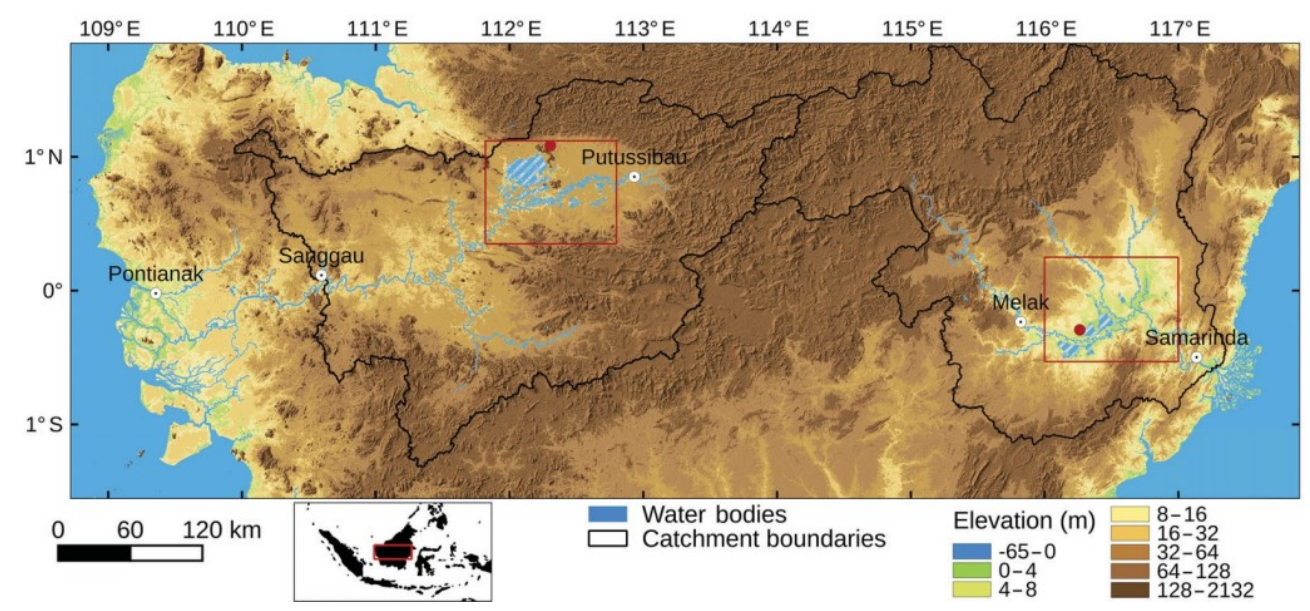

Figure 1. Catchment areas of the River Kapuas (left) and the River Mahakam (right), exemplifying lowland Rivers subject to semi-alluvial conditions. Adapted from Hidayat et al. [1].

\section{Nonuniform flow and backwater}

There can be a variety of reasons why the geological setting is such that the bed profile is far from parallel to the water surface. The building of reservoirs and dams to support irrigation limits the input of sediment to rivers at a global scale, which often causes channel incision and flattening of the bed slope. In an incising river, erosion resistant layers may create shallow sections which obstruct the development towards a smooth bed profile. Upstream and downstream of these erosion resistant layers, and near channel junctions where the river connects to lakes or tributaries, backwater and drawdown water level curves develop. The backwater length is inversely proportional to the bed slope, and becomes extremely large for small bed slopes. As a consequence, rivers crossing coastal and inland lowlands are often subject to the backwater effects from multiple causes.

Fig. 1 shows a digital elevation map of the central part of Borneo, exemplifying two catchments with rivers subject to complex discharge dynamics. Both catchments include an inland lake region that acts as a buffer for water and sediment. Hidayat et al. [3] showed how strongly the discharge dynamics is affected by backwater from multiple causes (Fig. 2). Only a very small part of the hysteresis in the stage-discharge curve can be attributed to diffusion of the passing discharge waves. The hysteretic behavior is different for subsequent discharge waves. Remarkably, the discharge estimates from a rating curve which ignore backwater effects better resembles discharge estimates from a rainfall-runoff model than more accurate estimations based on velocity measurements [4]. This suggests that when a rating curve is being developed in a river section with backwater, it predicts the part of the discharge dynamics that can be predicted from rainfall, and thus filters out the backwater effects. 


\section{Tidal modulation of the discharge}

When approaching the coast, river discharge generally becomes affected by the tidal motion, and vice versa, the tidal motion is affected by the river discharge [5]. Tides may propagate hundreds of kilometers inland, far beyond the region of salt intrusion, which may even hold for large river such as the Amazon and the Yangtze. In these tidal rivers, the discharge fluctuates not only over semidiurnal and diurnal cycles, but also over a spring-neap cycle. The tidal motion creates bed friction, which causes that the mean water surface slope required to drive a constant discharge across a tidal river is larger during spring tide than during neap tide. Towards spring tide, the water volume in the tidal river piles up until the increased surface slope is accomplished. The resulting fortnightly water level fluctuation can be seen as a forced wave, which can be manifest upstream of the location where diurnal and semidiurnal tides have become extinct [5].

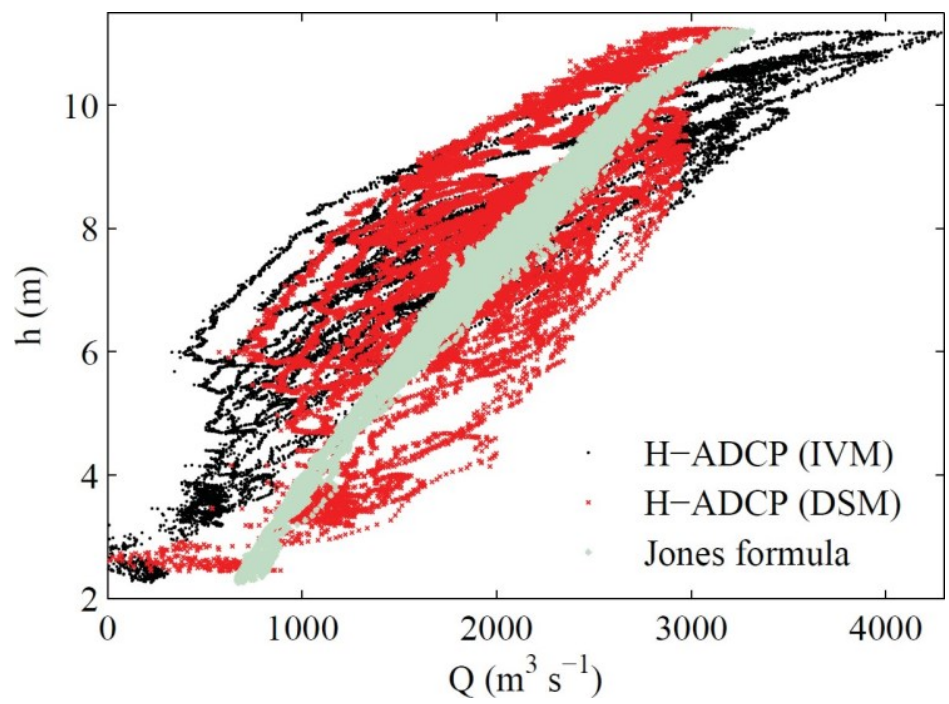

Figure 2. Stage (h) versus discharge (Q) from horizontal acoustic Doppler current profiler measurements at Melak station indicated in Fig. 1, based on an index velocity approach (IVM) and a semiDeterministic semi-Stochastic Model (DSM). Backwater effects from lakes and tributaries cause multiple hysteresis loops. Hysteresis from wave diffusion accounted for with Jones' formula only accounts for a small part of the hysteresis.

Tidal river discharge variation has a lagged response to discharge input from the catchment and tides at sea. The latter often can be predicted accurately using harmonic analysis. There are physics-based approaches to infer the river discharge from the ratio between water level amplitude in the tidal river and the amplitude at sea, referred to as tidal admittance ratio [7]. Such approach will be particularly successful in a single branch tidal river, as in branching channel systems the tidal propagation may vary across interconnected distributary channels. Leonardi et al. [8], for example, showed in a case study that the tidal velocity amplitude can even increase with increasing discharge. In branching channel networks, inferring discharge from water level information alone may be unfeasible even if multiple gauges are available. 


\section{Discharge monitoring based on flow velocity}

To overcome the ambiguity in stage-discharge relations introduced by backwater effects and tides, as explained in the previous sections, flow monitoring techniques are being employed. Flow velocity is often more closely related to discharge than water level, but the efforts needed to gauge the flow are larger. In shallow flows, the depth-mean flow velocity is often closely related to velocity at the surface, and non-intrusive monitoring approaches based on images of the water surface can be adopted relying on large-scale particle image velocimetry (LS-PIV) techniques [9], or ultra-high frequency (UHF) radar. LS-PIV is dependent on the weather conditions: it works best if the surface flow can be observed by the cameras. UHF radarcan operate day and night, but it requires a more substantial investment in radar equipment. In addition, some some surface roughness is required for Bragg scattering, which is a necessary condition for UHF radar to work.

Next to optical and radar-based approaches to monitor river discharge continuously, there are methods based on acoustics. A high accuracy can be obtained fromacoustic travel time meters, in which the cross-section averaged flow velocity is estimated from the difference in travel time between acoustic pulses traveling with and against the flow. This approach requires sound emitters and receivers on both sides of the river. Horizontally deployed acous- tic Doppler current profilers (H-ADCPs) can measure flow velocity profiles from a single location, along a horizontal range at a fixed height above the river bed. H-ADCPs have become increasingly popular, because of their relatively low installation and maintenance costs. The range across the river over which H-ADCPs can profile the flow depends on acoustic frequency. Low-frequency systems have a larger range but lower accuracy of the velocity estimates in an individual bins along the measurement profile.

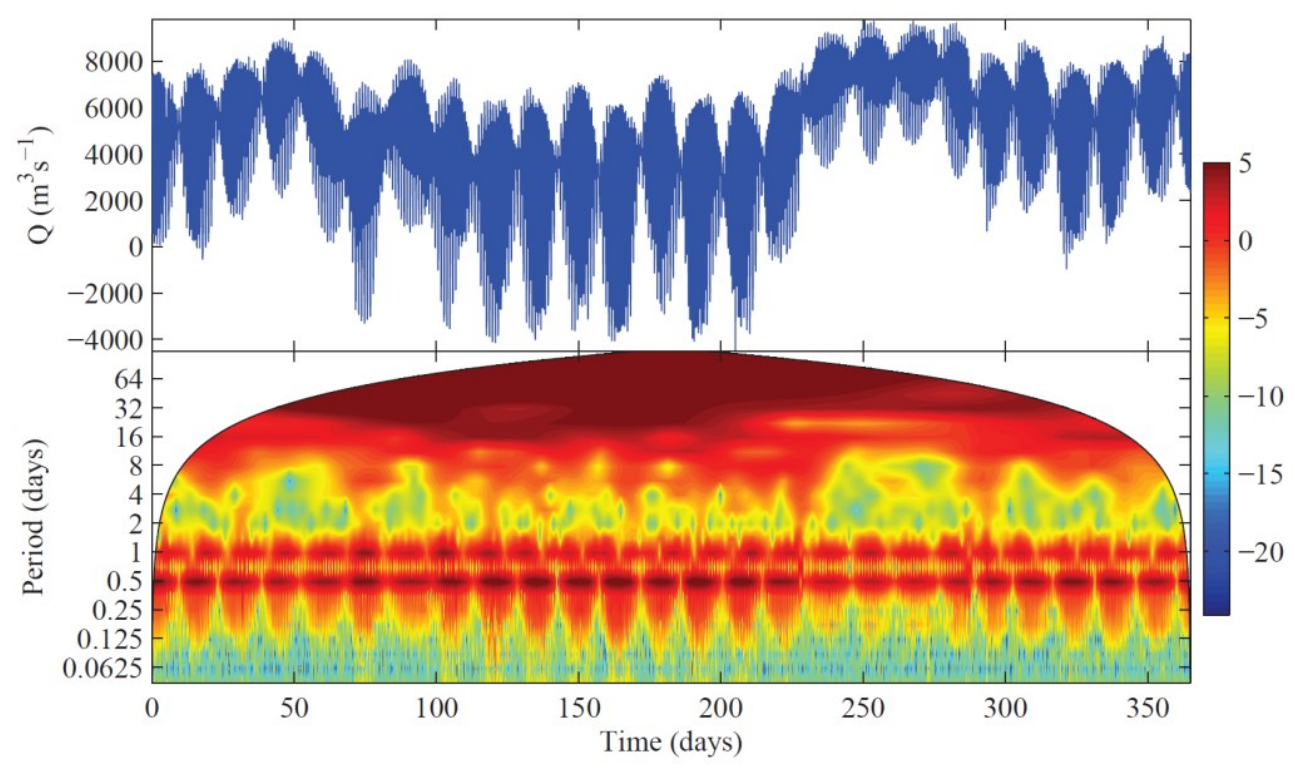

Figure 3. Continuous time-series of discharge in the Mahakam tidal river (top) and the corresponding wavelet spectrum (bottom). During high river discharge, the tidal amplitudes are smaller. Based on data from Samarinda station indicated in Figure 1. [cf. 6]. 

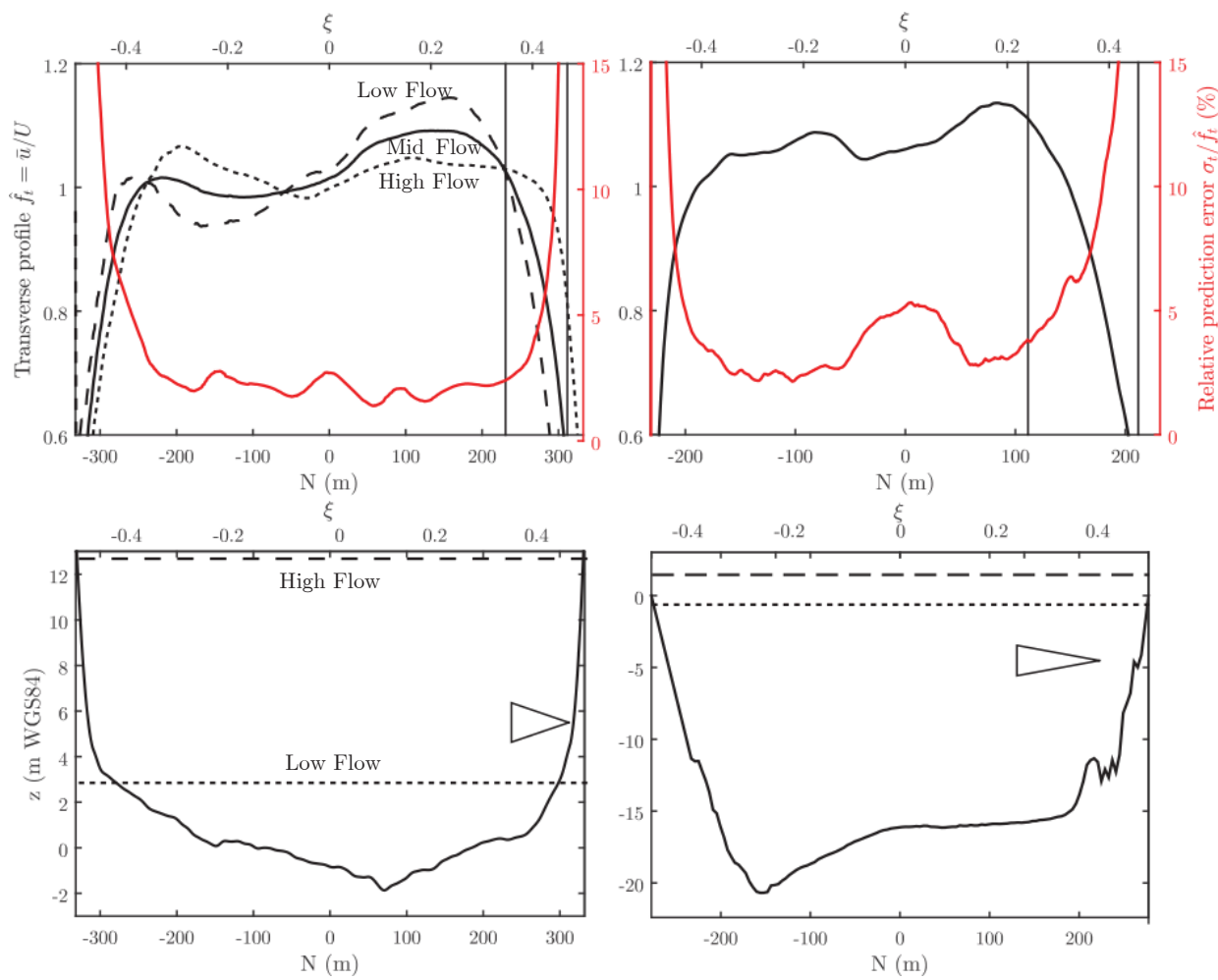

Figure 4. Top panels: Ratio of the depth-mean flow $\bar{u}$ and the cross-section averaged flow $U$, denoted as $\hat{f}_{t}$ across the channels at Sanggau (left) and Rasau Jaya (right), as well as the prediction error $\sigma_{t}$ as a percentage of $\hat{f}_{t}$. Bottom panels: channel geometry at Sanggau and Rasau Jaya. The triangles indicate the measurement ranges of the acoustic beams of the 600 $\mathrm{kHz} \mathrm{H}-\mathrm{ADCPs}$ deployed at both stations. Discharge estimates become increasingly inaccurate when they are inferred from flow velocity measurements collected closer to the banks. Adopted from Kästner et al. [2].

Kästner et al. [2] introduce a generic theoretical framework to estimate the accuracy of range-limited velocity profilers. Based on $\mathrm{H}-\mathrm{ADCP}$ measurements collected from stations with and without tides in the Kapuas River (locations indicated in Fig. 1), they highlighted the potential problems of gauging flow velocity with an H-ADCP deployed at the river bank. Translating H-ADCP measurements to discharge proceeds in two steps: (1) estimation of depth mean flow from flow at a single depth and (2) estimating cross-section averaged flow from the depth-mean flow. The first step generally introduces relatively little inaccuracy, because the mid-depth location of the H-ADCP measurement line is often close to the location where local velocity approximates the depth-mean velocity. When the log-law applies, this corresponds to a relative depth on 0.4 . The majority of the inaccuracy is caused by the difficulty to extrapolate the H-ADCP measurement data beyond the measurement range.

Fig. 4 shows the ratio of the depth-mean flow $\bar{u}$ and the cross-section averaged flow $U$, denoted as $\hat{f}_{t}$, across the channels at Sanggau and Rasau Jaya (Fig. 1). At Sanggau, where kinematic wave theory applies reasonably well, the cross-river profile of $\hat{f_{t}}$ is dependent on the river stage. This complicates the use of an index velocity approach, which is outperformed by a standard stage rating. At Rasau Jaya station, where tides are the primary agent governing flow variation, the cross-river profile of $\hat{f}_{t}$ is relatively steady after accounting for a time lag 
between variation of $\bar{u}$ and $U$. Fig. 4 also shows the prediction error ot relative to $\hat{f}$, revealing that the inaccuracy rapidly increases close to the river banks. This pattern is similar for Sanggau and Rasau Jaya.

Based on the error model, Kästner et al. [2] argue that H-ADCPs need to reach beyond the distance from the banks where the depth-mean velocity exceeds the cross-section average velocity. The location where this occurs can be estimated from a moving vessel survey prior to installation of the H-ADCP. Roughly, this corresponds to the location where the depth corresponds to the hydraulic radius. In conditions when a rating curve performs reasonably well, it is not easy to capitalize on the H-ADCP measurements to obtain improved accuracy.

\section{Conclusions}

In lowland plains, the bed slope of rivers becomes negligibly small and the flow is often nonuniform. Backwater from lakes and tributaries connected to the river cause hysteresis in stage-discharge relations. The length over which backwater acts is inversely proportional to bed slope, and therefore becomes larger for smaller slopes. Discharge dynamics at monitoring stations in coastal lowlands are therefore often subject to backwater effects from multiple sources. When the river is connected to the coastal ocean, tides and the effects of storm surges may add to the reasons for ambiguity in relations between stage and river discharge.

Accurate measurement of river discharge in coastal lowland plains may require collecting continuous flow measurements. Acoustic Doppler current profilers are increasingly being deployed for discharge estimation, because they can measure profiles of flow velocity from a single gauge location. However, the profiling range is often limited to a small fraction of the cross-section. A recent error analysis reveals that the accuracy of discharge estimates is critically dependent on the extent of the acoustic profiling range. A rule of thumb is that the H-ADCP needs to reach beyond the distance from the river bank where the depth mean velocity exceeds the cross-section averaged velocity.

\section{Acknowledgements}

This research was supported by the Royal Netherlands Academy of Arts and Sciences (KNAW) project SPIN3-469 JRP-29. B. Vermeulen and K. Kästner are acknowledged for adjusting the figures of the original publications.

\section{References}

1. Hidayat, H. and Teuling, A.J. and Vermeulen, B. and Taufik, M. and Kästner, K. and Geertsema, T.J. and Bol, D.C.C. and Hoekman, D.H. and Sri Haryani, G. and Van Lanen, H.A.J. and Delinom, R.M. and Dijksma, R. and Anshari, G.Z. and Ningsih N.S. and Uijlenhoet, R. and Hoitink, A.J.F. (2017). Hydrology of inland tropical lowlands: the Kapuas and Mahakam wetlands. Hydrology and earth system sciences, 21(5), 2579.

2. Kästner, K., A.J.F. Hoitink, Torfs, P. J. J. F., Vermeulen, Ningsih, N. S., \& Pramulya, M. (in press). Prerequisites for accurate monitoring of river discharge based on fixed-location velocity measurements, Water Resources Research.

3. Hidayat, H., Vermeulen, B., Sassi, M. G., Torfs, P. J. J. F., \& Hoitink, A.J.F. (2011). Discharge estimation in a backwater affected meandering river. Hydrology and earth system sciences, 15(8), 2717-2728.

4. Hidayat, H. (2013), Runoff, discharge and flood occurrence in a poorly gauged tropical basin: the mahakam river, kalimantan, Ph.D. thesis, Hydrology and Quantitative Water 
Management Group, Department of Environmental Sciences, Wageningen University.

5. Hoitink, A.J.F. and Jay, D.A. (2016). Tidal river dynamics: implications for deltas. Reviews of Geophysics, (54):240-272.

6. Sassi,M.G., A.J.F.Hoitink, B. Vermeulen, andH.Hidayat(2011), Discharge estimation from $\mathrm{H}-\mathrm{ADCP}$ measurements in a tidal river subject to sidewall effects and a mobile bed, Water Resources Research, 47(6).

7. Moftakhari, H. R., D. A. Jay, S. A. Talke, T.Kukulka, and P.D. Bromirski (2013), A novel approach to flow estimation in tidal rivers, WaterResources Research, 49(8), 4817-4832.

8. Leonardi, N., A. S. Kolker, and S. Fagherazzi (2015), Interplay between river discharge and tides in a delta distributary, Advances in Water Resources, 80, 69-78.

9. Muste, M. and Fujita, I. and Hauet, A. (2008), Large-scale particle image velocimetry for measurements in riverine environments, Water Resources Research, 44(4). 